\title{
Cursos superiores de tecnologia no contexto da internacionalização e da expansão da educação profissional e tecnológica no Estado de São Paulo ${ }^{1}$
}

Higher technology courses in the context of internationalization and the expansion of vocational and technological education in the State of São Paulo

\author{
Cursos superiores de tecnología en el contexto \\ de la internacionalización y de la expansión de la \\ educación vocacional y tecnológica en el Estado de \\ São Paulo
}

Sueli Soares dos Santos Batista ${ }^{2}$

Emerson Freire ${ }^{2}$

Darlan Marcelo Delgado ${ }^{2}$

DOI: http://dx.doi.org/10.20435/serie-estudos.v25i54.1381

Resumo: O que significava criar instituições de ensino superior como centros tecnológicos
formadores de tecnólogos no fim dos anos 1960 ? Que sentido foi dado a essa concepção ao
longo da implementação e consolidação dos cursos superiores de tecnologia, considerando a
internacionalização e a expansão da educação profissional e tecnológica? O presente estudo
destaca a trajetória e o significado dos cursos superiores de tecnologia desde sua origem, passando
por suas transformações ao longo do processo de expansão das redes de educação profissional e
tecnológica nos anos 2000 , quando houve uma ênfase nesses cursos como parte das estratégias
nacionais de internacionalização da educação. A relevância do que se desenvolve neste artigo,
enfatizando-se a experiência paulista, dá-se por conta dos poucos estudos relacionados a esses
cursos enquanto modalidade de ensino superior e também porque as políticas educacionais
pós-2016 sinalizam para uma reestruturação das universidades e o desmonte das condições
para o desenvolvimento da pesquisa, colocando no centro das reformulações legais e disputas

1 Apoio FAPESP. Processo n. 2018/03106-8.

2 Centro Estadual de Educação Tecnológica Paula Souza (CEETEPS), São Paulo, São Paulo, Brasil. 
institucionais a ênfase na profissionalização e na internacionalização como estratégias de formação e fornecimento de mão de obra para o mercado de trabalho em escala global.

Palavras-chave: cursos superiores de tecnologia; educação profissional e tecnológica; internacionalização da educação superior.

\begin{abstract}
What does it mean to create higher education institutions as technological centers to train technologists in the late 1960s? What meaning has been given to this conception throughout the implementation and consolidation of higher technological courses, considering the internationalization and expansion of vocational and technological education? The present study highlights the trajectory and meaning of higher education technological courses since their origin, passing through their transformations during the expansion process of vocational and technological education networks in the 2000s, when there was an emphasis on these courses as part of the national strategies of internationalization of education. The relevance of what is developed in this article is due to the few studies related to these courses as a higher education modality and also because the post-2016 educational policies signal for the restructuring of universities and the dismantling of the conditions research development, placing at the heart of legal reformulations and institutional disputes the emphasis on professionalization and internationalization as strategies for training and supplying labor to the global labor market.
\end{abstract}

Keywords: higher technology courses; vocational and technological education; internationalization of higher education.

Resumen: ¿Qué significó crear instituciones de educación superior como centros tecnológicos que capacitaron a tecnólogos a fines de la década de 1960? ¿Qué significado se le ha dado a esta concepción a lo largo de la implementación y consolidación de cursos de tecnología superior, considerando la internacionalización y expansión de la educación profesional y tecnológica? El presente estudio destaca la trayectoria y el significado de los cursos de tecnología de educación superior desde su origen, a través de sus transformaciones a lo largo del proceso de expansión de las redes de educación profesional y tecnológica en la década de 2000, cuando se hizo hincapié en estos cursos como parte de las estrategias nacionales de internacionalización de la educación. La relevancia de lo que se desarrolla en este artículo se debe a los pocos estudios relacionados con estos cursos como una modalidad de educación superior y también porque las políticas educativas posteriores a 2016 señalan una reestructuración de las universidades y el desmantelamiento de las condiciones para el desarrollo de la investigación, colocando en el centro de las reformulaciones legales y las disputas institucionales el énfasis en la profesionalización y la internacionalización como estrategias para capacitar y suministrar mano de obra al mercado laboral mundial.

Palabras clave: cursos de alta tecnología; educación profesional y tecnológica; internacionalización de la educación superior.

\title{
1 INTRODUÇÃO
}

O marco da criação dos Cursos Superiores de Tecnologia (CST) se deu com a introdução da Lei de Diretrizes e Bases da Educação Nacional de 1961 (Lei n. 4.024), que trouxe em seu artigo 104 a permissão para que conselhos de educação autorizassem o funcionamento de cursos experimentais, com currículos, métodos 
e períodos próprios. Essa foi uma espécie de flexibilização que teria ensejado a proposta de criação do Curso de Engenharia de Operação, a qual foi aprovada pelo Conselho Federal de Educação (CFE), em 1963. Autorizando cursos dessa natureza com duração de três anos, o CFE passou nas décadas futuras a normatizar essa oferta educativa (MACHADO, 2008). O CFE já vinha se fortalecendo desde a aprovação da LDB, em 1961, quando passou a deliberar sobre abertura e funcionamento de instituições de ensino superior (MARTINS, 2009).

Esse processo estava diretamente ligado ao Plano Trienal de Educação de 1962, em que se enfatizava a relação entre a educação e as estratégias do nacionalismo-desenvolvimentista quanto à política de ciência e tecnologia. Nos termos desse Plano, o Ministério da Educação (MEC) deveria influir diretamente nas universidades, escolas superiores e institutos técnicos, visando ao desenvolvimento da ciência e do ensino de ciências. O Plano destacava a necessidade primordial do aumento do número de cientistas e técnicos qualificados nas escolas superiores e nos estabelecimentos de pesquisa fundamental e aplicada (SANTOS, 2019).

A Reforma Universitária de 1968, ao abrir caminhos para uma formação de nível superior de curta duração e de caráter fundamentalmente aplicado, coloca em pauta e atualiza a intrigante consideração de Anísio Teixeira de que "[...] a história da ideia de universidade no Brasil revela uma singular resistência do país em aceitá-la" (TEIXEIRA, 1969, p. 231). Do mesmo modo, é possível afirmar, observando a trajetória dos cursos superiores de tecnologia, que os estudos sobre a educação superior não contemplam de maneira satisfatória a experiência da graduação tecnológica que completa meio século em 2019.

O cenário nacional marcado pelo esforço racionalizador numa vertente conservadora foi fundamental para os cursos dessa natureza, perante os quais a comunidade acadêmica e diversos segmentos profissionais se colocavam criticamente. As tentativas de implementar estratégias de modernização da educação no Brasil seguindo modelos americanos já se iniciavam na segunda metade dos anos 1940, mas foi na década de 1960 que as condições políticas permitiram essa adequação (SANTOS, 2019, OLIVEIRA, 2003). Os acordos Ministério da Educação-Agência Norte-Americana para o Desenvolvimento Internacional (MEC-USAID) consolidaram esse processo.

Nesses acordos, a instituição educacional americana foi convidada para dar suporte técnico-financeiro no sentido de assistir os conselhos e secretarias estaduais 
de educação, treinando equipes de técnicos brasileiros em planejamento de ensino e em outras atividades de gestão e avaliação educacional, sobretudo no que se refere à educação superior. Era o nacional-desenvolvimentismo em pleno funcionamento.

Em um dos convênios inseridos nesse pacote MEC-USAID, em 1967, afirmase que o Brasil pretendia aproveitar a experiência de outros países para realizar planejamento em curto e longo prazo do sistema do ensino superior, bem como aumentar a eficiência dos seus métodos de trabalho e de seus diversos programas de maneira coordenada. Uma das premissas do treinamento realizado pelos técnicos do USAID no Brasil se referia à descentralização dos sistemas de ensino, defendendo-se a necessidade de passar aos estados mais responsabilidades na esfera educacional. As experiências educacionais americanas nos Community Colleges não teriam influenciado a concepção das Faculdades de Tecnologia (Fatec) do Centro Estadual de Educação Tecnológica Paula Souza (Ceeteps) caso não existissem os acordos MEC-USAID. Essa concepção de matriz norte-americana foi intensamente defendida pelo governo brasileiro nos anos 1990, algo que preparou a expansão dos cursos de tecnologia em São Paulo e as escolas da rede federal de EPT. A proposta era de que a profissionalização pudesse migrar para o nível superior num formato distinto construído pela universidade, com menos custos, em médio e longo prazo, para a pesquisa e para a formação de professores, esses sobretudo oriundos do setor produtivo (CASTRO, 2000).

O presente estudo destaca a trajetória e o significado dos cursos superiores de tecnologia, desde sua origem, passando por suas transformações ao longo do processo de expansão das redes de educação profissional e tecnológica nos anos 2000, em que houve uma ênfase nesses cursos como parte das estratégias nacionais de internacionalização da educação. A relevância do que se desenvolve neste artigo se dá por conta dos poucos estudos relacionados a esses cursos enquanto modalidade de ensino superior e também porque as políticas educacionais pós-2016 sinalizam para uma reestruturação das universidades, o desmonte das condições para o desenvolvimento da pesquisa, colocando no centro das reformulações legais e disputas institucionais a ênfase na profissionalização e na internacionalização como estratégia de formação e fornecimento de mão de obra para o mercado de trabalho em escala global.

Quanto aos cinquenta anos dos cursos superiores de tecnologia coincidindo com os cinquenta anos das Faculdades de Tecnologia (Fatec) vinculadas ao 
Ceeteps, em São Paulo, é apresentada essa especificidade na primeira seção deste estudo, sendo considerado o contexto político e econômico dos anos 1960, em que esses cursos e essa instituição foram oficializados simultaneamente.

Na segunda seção, são apresentados e discutidos os indicadores da expansão da oferta desses cursos no contexto da expansão das redes de educação profissional e tecnológica a partir dos anos 2000. Trata-se não somente da expansão da quantidade de vagas e cursos normatizados pelos Catálogos dos Cursos Superiores de Tecnologia, mas da tentativa de inserir essa modalidade educativa numa política ampla de ciência, tecnologia e inovação, sendo esses cursos considerados fundamentais para a internacionalização da educação no período que se estende até meados da década de 2010. Esse aspecto se encontra desenvolvido na terceira seção do artigo articulado ao movimento pós-expansão da Educação Profissional e Tecnológica (EPT), em que as reformas educacionais em curso, no sentido de uma modernidade conservadora, discutem o papel da universidade, do ensino superior e da profissionalização em todos os níveis, da qualificação aos mestrados e doutorados profissionais.

\section{CENTRO ESTADUAL DE EDUCAÇÃO TECNOLÓGICA PAULA SOUZA E OS CURSOS SUPERIORES DE TECNOLOGIA}

Nos anos 1960, alegando a longa duração e o alto custo dos cursos de Engenharia, a Diretoria de Ensino Superior, vinculada ao Ministério da Educação, propôs o currículo de novos cursos que fossem na contramão daqueles já existentes. Em 1969, em São Paulo, seria criado o Centro Estadual de Educação Tecnológica de São Paulo, atualmente denominado de Centro Estadual de Educação Tecnológica Paula Souza (Ceeteps). Essa foi uma decisão do Conselho Estadual de Educação de São Paulo por meio do Parecer 384/69. Naquela ocasião, ainda se denominava técnico de nível superior, antes que fosse cunhada a expressão "tecnólogo" para os egressos dos CST (OLIVEIRA, 2003).

Foram criados cursos superiores de curta duração, com o mesmo objetivo, ou seja, de oferecem uma forma rápida, com menor custo e atendendo às demandas imediatas do setor produtivo, também em 1969, na Escola Técnica Federal do Rio de Janeiro. Assim, a política de acesso ao ensino superior de caráter profissionalizante esteve inicialmente vinculada às instituições diferentes das universidades, como é o caso das Escolas Técnicas Federais e das Faculdades de Tecnologia do Ceeteps. 
O surgimento desses cursos está entrelaçado à Reforma Universitária de 1968, que buscava a solução para a formação subordinada diretamente às necessidades do setor produtivo com formação fora das universidades. O governo militar daquele período, para dar embasamento científico a essa reforma, encomendou vários estudos que geraram diagnósticos e recomendações, sugerindo a reforma do ensino superior que deveria ter objetivos práticos e adaptar seus conteúdos às metas do desenvolvimento nacional. Seria necessário expandir esse ensino com o menor custo financeiro (MARTINS, 2009).

O Ceetesp teve participação substancial, principalmente no contexto paulista, para a constituição dos cursos superiores de tecnologia no país. Sua idealização e criação, no governo de Roberto Costa Abreu Sodré, inspirou-se no College of Advanced Technology ou Junior College, dos EUA e também no Institute Supérieure de Technologie, da França (MOTOYAMA, 1995, p. 88; BRANDÃO, 2007).

Os junior colleges, surgidos nos EUA no fim do século XIX, são experiências originais de cursos de caráter profissionalizante ofertados em instituições pequenas com condições de oferecer formação profissional de natureza básica. Caracterizando-se pela formação mais prática e imediatista, serão continuados pelos community colleges, tipo de escola e de formação celebrada como importante para a expansão do ensino superior no Brasil (CASTRO, 2000). Os community colleges desenvolvidos a partir do início do século XX oferecem cursos de nível superior de dois anos, procurando atender às necessidades de uma comunidade específica. Isso faz com que sejam experiências que inspiraram as políticas educacionais brasileiras de expansão do ensino superior, menos como formato a ser copiado e mais como concepção educacional para atender segmentos mais pobres da sociedade (CARVALHO, 2005).

Quando a Escola Politécnica deixou o prédio da Praça Coronel Fernando Prestes, indo para o campus da Cidade Universitária, vislumbrou-se a oportunidade de ocupar aquele imóvel, então vago e à disposição do governo do estado, construindo o que fora chamado de um "grande centro de estudos tecnológicos" (MOTOYAMA, 1995, p. 88).

O professor Paulo Ernesto Tolle, um dos secretários do governo Sodré e que havia sido ex-diretor do ITA e docente na Universidade da Califórnia em Berkeley, foi um dos mentores desse modelo educacional tecnológico do Ceeteps, sendo posteriormente convidado a integrar uma comissão para estudar a reforma do ensino superior, a qual resultou na Lei n. 5.540, de 1968, da Reforma Universitária. 
O entendimento era de que essa formação específica, bem como a educação como um todo, precisaria não se afastar das atividades culturais. Assim, além do Ceeteps, fazem parte do mesmo momento a criação da Fundação Padre Anchieta, da TV Educativa, do Museu da Imagem e do Som, do Festival de Inverno de Campos do Jordão e do próprio Museu de Arte Sacra, na Avenida Tiradentes, próximo do Centro Paula Souza, entre outras ações nesse sentido (MOTOYAMA, 1995). Segundo as palavras do próprio Abreu Sodré: "A minha preocupação no setor da cultura e da educação, que inclui a parte tecnológica, foi muito grande: 32\% do meu orçamento era dedicado ao processo de aprimoramento das inteligências" (MOTOYAMA, 1995, p. 92).

O ex-governador, na entrevista que concedeu para o livro que narra a história do Ceeteps, deixou clara a falta de interesse por parte dos empresários, cujo portavoz era a Fiesp, na criação de um centro de ensino tecnológico. O financiamento foi totalmente estatal.

Segundo o relato do prof. Paulo Ernesto Tolle, as origens do Ceeteps e, assim, dos cursos superiores de tecnologia, remontam às discussões e ideias iniciadas no ano de 1963. Contudo a primeira ação concreta no sentido de dar encaminhamento ao projeto dos cursos de tecnologia foi a publicação da Resolução n. 2001, de 15 de janeiro de 1968, a qual criou um grupo de trabalho cujos membros estudavam a formulação de cursos superiores de tecnologia com duração de dois a três anos. Nesse momento, o prof. Paulo Ernesto Tolle era o presidente do Conselho Estadual de Educação de São Paulo. O relatório gerado por esse grupo de trabalho apresentava uma proposta de criação de cinco cursos: i) curso superior de técnico em eletrônica, nas modalidades de comunicações e de eletrônica industrial; ii) o de técnico em eletrotécnica com máquinas elétricas e o de transmissão de eletricidade; iii) o de técnico superior em mecânica, especialidade de desenhista-projetista; iv) o de técnico superior de construção civil; e v) uma Escola Superior de Tecnologia Mecânica (MOTOYAMA, 1995).

Uma segunda comissão foi criada, designada de Grupo de Trabalho para a Promoção do Ensino Tecnológico, sendo este formalmente estabelecido por meio do Decreto n. 49.327, de 21 de fevereiro de 1968. Os seus membros integrantes, oriundos de diversas instituições, deveriam examinar a possibilidade de instalação e funcionamento ainda no ano letivo de 1968 de até quatro Faculdades de Tecnologia (Fatec) e suas localizações em diferentes regiões do estado. O grupo não obteve o êxito esperado, inaugurando-se apenas a Faculdade de Tecnologia 
de Bauru, inicialmente pela iniciativa privada, convertendo-se depois na Fundação Educacional de Bauru, que oferecia cursos superiores de dois anos.

Havia dificuldade em convencer as prefeituras dos municípios que demandavam ensino superior sobre as vantagens da adoção do modelo de ensino tecnológico, o que levou à necessidade de criar uma faculdade de tecnologia estadual, a qual serviria de modelo para os municípios. É a partir dessa percepção que se estabeleceu uma terceira comissão, presidida pelo prof. Oswaldo Fadigas Fontes Torres e integrada pelos professores Vicente Chiaverini (Politécnica) e Octávio Gaspar de Souza Ricardo (CEE). Essa Comissão Especial foi incumbida da missão de elaborar o projeto de um instituto tecnológico educacional do estado, o qual deveria proporcionar habilitações intermediárias de grau superior nos campos prioritários da tecnologia, bem como formar os docentes para lecionar no ensino técnico (MOTOYAMA, 1995). Dessa forma, deu-se prosseguimento às ações que culminaram com a promulgação do Decreto-Lei de 6 de outubro de 1969 (criando o Centro Estadual de Educação Tecnológica de São Paulo). O Centro iniciou suas atividades com uma faculdade de tecnologia em São Paulo e, ainda, na gestão de Abreu Sodré, uma em Sorocaba.

Todavia foi somente com o Parecer CFE 1.060/73 que se formalizou a nomenclatura de Cursos Superiores de Tecnologia (CST), sendo seus egressos denominados de tecnólogos (MACHADO, 2008). O tecnólogo surge como uma espécie de intermediário entre o engenheiro e o cientista, com uma formação voltada para a aplicação prática dos conhecimentos. O Ceeteps, já no seu início, colocou-se de maneira crítica aos cursos para formação de tecnólogos como cursos de curta duração, defendendo sua especificidade tecnológica como o fator mais relevante (GONÇALVES, 2007).

Em seus primórdios, pensava-se a instituição como instrumento de uma verdadeira revolução educacional orientada ao desenvolvimento econômico e social, oferecendo cursos de nível superior em contextos não universitários.

O surgimento e a continuidade dos cursos superiores de tecnologia são um processo que não se dá sem contradições, passando esses cursos por transformações e sofrendo resistência por parte dos conselhos profissionais e pelas mais variadas formas de preconceito produzidas a partir da cultura do bacharelado ou da ideia de que se trata ainda de uma profissionalização desvinculada da formação em nível superior. De acordo com Machado (2008, p. 13): 
Prevaleceu, até o presente momento, uma lógica que os vincula às expectativas subjetivas e institucionais de apropriação de conhecimentos que possam ser imediatamente aplicáveis a atividades práticas específicas; a nichos emergentes do mercado de trabalho; e a demandas por obtenção rápida de um título acadêmico de nível superior de amplos segmentos da população brasileira desprovidos dos recursos educacionais ou econômicos que viabilizem seu acesso aos cursos de bacharelado.

No caso dos conselhos profissionais, é importante considerar que as questões relativas às habilitações, à capacitação e à certificação estão sempre sendo monitoradas e discutidas e, dependendo das necessidades avaliadas por esses conselhos, passam por processos de renovação. O Conselho Federal de Engenharia (CONFEA), no exercício da lei, e os Conselhos Regionais acabam sendo os órgãos regulamentadores e reguladores desse processo quanto à área da construção civil. A formação desses tecnólogos precisa, então, estar afinada com essas diretrizes histórica e socialmente construídas pelas categorias profissionais ligadas à Engenharia, à Arquitetura e à Agronomia. No caso de outras habilitações profissionais em que essa organização por conselhos não está bem estruturada, a formação e a inserção do tecnólogo encontram menos resistências.

No ano de 1979, o CONFEA, por meio da Resolução 262, especificou as atribuições dos técnicos de 20 Grau nas áreas de Engenharia, Arquitetura e Agronomia. A necessidade de estabelecer as atribuições desses técnicos teve como ponto de partida o fato de que esse profissional, em vista de sua escolarização em nível de 2 o Grau ou equivalente, seria habilitado ao exercício de atividades intermediárias, entre as que são privativas dos profissionais de nível superior nessas áreas e as em que, embora os profissionais sejam qualificados, carecem de regulamentação para exercê-las. E, no caso do tecnólogo, enquanto profissional com diploma de nível superior, a Resolução 313, de 26 de setembro de 1986, é a que ainda atualmente dispõe sobre as atribuições dos Tecnólogos, considerandose os "limites de sua formação" (CONFEA, 1986).

\section{RESSIGNIFICAÇÃO DOS CURSOS SUPERIORES DE TECNOLOGIA NO CONTEXTO DA EXPANSÃO DA EDUCAÇÃO PROFISSIONAL E TECNOLÓGICA}

Se o interesse no fim dos anos 1960 era de criar e defender uma instituição pública de qualidade que fosse um centro de estudos tecnológicos e formador dos profissionais tecnólogos, esse desafio ainda está posto, na medida em que 
os cursos superiores de tecnologia e seus egressos continuam enfrentando inúmeras dificuldades quanto à comparação com os bacharéis, quanto ao caráter tecnológico dos cursos e quanto à sua inserção no mercado de trabalho, exigindo uma frequente reformulação de suas concepções.

Os cursos de tecnologia, ao longo dos anos 1990, foram oferecidos com duração média de dois anos por instituições privadas, e, nos anos 2000, passaram a fazer parte de um processo de expansão das redes públicas de EPT. As leituras e discussões sobre o trabalho como princípio educativo e a formação integral foram as bases teórico-metodológicas desse processo de expansão, as quais têm os decretos federais 2.208/97 e 5.154/04 como marcos reguladores que demonstram posicionamentos conflitantes quanto ao lugar que a profissionalização deve ocupar na escolarização.

Entendida muitas vezes como uma formação tecnicista, a formação nos cursos tecnológicos, por conta da sua ressignificação, sobretudo a partir dos anos 2000, passou a ser concebida de maneira ampliada, inserida dentro de uma política pública de expansão da educação profissional de nível médio e superior. Discutindo essa perspectiva ampliada para os cursos de tecnologia, Batista (2012) reforça que eles devem ser concebidos e organizados de modo a proporcionar formação mais abrangente:

Contrariando os preconceitos de uma cultura do bacharelado que opõe formação tecnológica e universitária, os cursos para formação de tecnólogos têm priorizado a democratização do acesso e a empregabilidade, a parceria com o setor produtivo, sem descuidar da qualidade e de um aprofundamento na discussão sobre a dimensão social da tecnologia, que não diz respeito apenas às habilidades de manuseio de equipamentos. A separação entre uma formação humanística, enquanto formação teórica e básica, como se ela fosse incompatível com uma formação tecnológica, essencialmente prática, carece de fundamentação epistemológica e comprovação empírica. (BATISTA, 2012, p. 35).

A despeito das representações sociais relacionadas aos cursos de tecnologia e seus egressos, no contexto da expansão da EPT colocada em curso nos anos 2000, ressalta-se a reconfiguração desses cursos numa política pública não só de formação profissional, mas de uma das faces da política de ciência, tecnologia e inovação em diálogo com as diretrizes internacionais. A partir do modelo de expansão da EPT, o Banco Mundial viabilizou no Brasil parte de suas diretrizes, 
sendo implementadas à medida que o Programa Nacional de Acesso ao Ensino Técnico e Emprego (PRONATEC) e o Programa de Integração da Educação Profissional ao Ensino Médio (PROEJA) possibilitaram o processo de diversificação do oferecimento da educação profissional; o Programa Universidade para Todos (PROUNI) e o Reestruturação e Expansão das Universidades Federais (REUNI) também contribuíram com a expansão da educação superior tanto no âmbito público quanto privado (FIALA, 2016).

À educação profissional foi acrescentada a expressão "tecnológica" no sentido de enfatizar que essa educação procurava estar pari passu com os padrões de qualidade, produtividade e competitividade dos países desenvolvidos (OLIVEIRA, 2012). No entanto a expressão "educação tecnológica" esteve desde o início no nome do Ceeteps, que ao longo de suas primeiras décadas, procurou oferecer cursos de tecnologia não propriamente de curta duração, mas que tivessem densidade tecnológica. O curso superior de tecnologia ou cursos tecnológicos teriam, assim, uma natureza não somente técnica, mas também científica, caracterizando-se por sua densidade tecnológica construída pela dimensão aplicada da pesquisa. Mesmo assim, parece ainda incipiente a discussão sobre a expressão "tecnológica" em seu sentido mais amplo e verticalizado, pois muitas vezes o sufixo "tecnológico" que acompanha a nomenclatura dos diversos cursos oferecidos nessa modalidade de ensino superior vem considerado apenas no sentido utilitário da tecnologia, como mero aprendizado de técnicas e tecnologias a serem aplicadas, destituído dos sentidos (geo)político e cultural pertencentes ao próprio fazer tecnológico. Isso significa que os cursos de tecnologia necessariamente estão vinculados não só aos modelos tecnocientíficos vigentes em diferentes momentos e lugares, mas às diferentes concepções de tecnologia que perpassam esses modelos, inclusive considerando o contexto internacional.

De certa forma, tentando dar conta da questão, esse foi um dos objetivos da construção e publicação dos catálogos dos cursos superiores e tecnológicos ao promoverem a reorganização dos cursos técnicos e tecnológicos não só por áreas profissionais, mas por eixos tecnológicos. Publicado pela primeira vez em 2006, o Catálogo Nacional de Cursos Superiores de Tecnologia (CNCST) é uma das dimensões estruturantes no processo de organização e gestão do sistema de ensino superior tecnológico no país. Esse documento produzido pelo MEC, sob organização da Secretaria de EPT e da Secretaria de Regulação e Supervisão do 
Ensino Superior, traz diretrizes para a organização curricular e a implantação dos cursos de graduação tecnológica. Em função dessa regulação, foi possível, a partir de 2007, aplicar o Exame Nacional de Desempenho dos Estudantes (Enade) em alunos de cursos superiores de tecnologia.

O caráter regulador e estruturante do catálogo se refere à expansão dessa oferta educativa, que, segundo o Censo do Instituto de Estudos e Pesquisas Educacionais Anísio Teixeira (INEP), de 2007 a 2017, teve aumento de mais de $140 \%$ de matrículas.

Essa expansão dos cursos superiores de tecnologia (CST) no país e no Estado de São Paulo é um fato verificável por meio dos dados disponibilizados nos Censos da Educação Superior, realizados anualmente pelo INEP-MEC. Em 2017, o INEP (2011-2018) registrou 617.317 alunos ingressantes nos cursos de tecnologia no país, com um aumento de 16,2\% em relação ao ano anterior. Porém os dados não revelam um fenômeno uniforme (ao longo dos anos) nem homogêneo (ao se comparar as distintas categorias administrativas pública e privada).

Ao se tomar a presente década, sendo 2011 o ano-base com dados disponíveis consolidados até o ano de 2018, foram selecionadas para análise três variáveis: o número de cursos ofertados, a quantidade de vagas ofertadas e as matrículas efetivadas em cursos superiores de tecnologia no país. Em relação ao estado de São Paulo, restringimos a análise ao número de matrículas.

A partir dos dados da Tabela 1, é possível verificar que, em 2011, foram ofertados no país 5.478 cursos, chegando a um total de 7.810 em 2018. Para essa variável, em particular, a dinâmica de crescimento é uniforme no sentido de haver ocorrência de aumentos sucessivos ano a ano, a uma média de 5,2\% de crescimento anual. O crescimento médio do número de cursos ofertados pela iniciativa privada, de 5,6\% a.a., é superior à taxa média de crescimento dos cursos ofertados por instituições públicas no mesmo recorte temporal, de 3,4\% a.a. É claro, há o predomínio da participação do setor privado na oferta de cursos, com uma média de $82,5 \%$ ao longo desses anos, contra 17,5\% das instituições públicas. 
Tabela 1 - Cursos Superiores de Tecnologia (CST) ofertados - Brasil - 2011-2018

\begin{tabular}{|l|cccccccc|c|}
\hline Categorias & \multicolumn{7}{|c|}{ Anos } & Taxas \\
\cline { 2 - 10 } Administrativas & $\mathbf{2 0 1 1}$ & $\mathbf{2 0 1 2}$ & $\mathbf{2 0 1 3}$ & $\mathbf{2 0 1 4}$ & $\mathbf{2 0 1 5}$ & $\mathbf{2 0 1 6}$ & $\mathbf{2 0 1 7}$ & $\mathbf{2 0 1 8}$ & Médias $^{(\mathbf{1})}$ \\
\hline Pública & $\mathbf{9 6 8}$ & $\mathbf{1 . 1 1 7}$ & $\mathbf{1 . 1 4 6}$ & $\mathbf{1 . 1 5 7}$ & $\mathbf{1 . 1 5 8}$ & $\mathbf{1 . 1 8 6}$ & $\mathbf{1 . 1 9 7}$ & $\mathbf{1 . 2 1 3}$ & - \\
\hline Pública $(\% / T)$ & $17,7 \%$ & $18,7 \%$ & $18,4 \%$ & $18,0 \%$ & $17,5 \%$ & $17,4 \%$ & $17,1 \%$ & $15,5 \%$ & $\mathbf{1 7 , 5 \%}$ \\
\hline Pública $(\Delta \%)$ & - & $15,4 \%$ & $2,6 \%$ & $1,0 \%$ & $0,1 \%$ & $2,4 \%$ & $0,9 \%$ & $1,3 \%$ & $\mathbf{3 , 4 \%}$ \\
\hline Federal & 541 & 574 & 591 & 607 & 630 & 645 & 663 & 684 & - \\
\hline Estadual & 356 & 398 & 417 & 457 & 469 & 480 & 486 & 485 & - \\
\hline Municipal & 71 & 145 & 138 & 93 & 59 & 61 & 48 & 44 & - \\
\hline Privada & $\mathbf{4 . 5 1 0}$ & $\mathbf{4 . 8 5 2}$ & $\mathbf{5 . 0 7 8}$ & $\mathbf{5 . 2 5 6}$ & $\mathbf{5 . 4 6 0}$ & $\mathbf{5 . 6 4 2}$ & $\mathbf{5 . 8 0 8}$ & $\mathbf{6 . 5 9 7}$ & - \\
\hline Privada $(\% / T)$ & $82,3 \%$ & $81,3 \%$ & $81,6 \%$ & $82,0 \%$ & $82,5 \%$ & $82,6 \%$ & $82,9 \%$ & $84,5 \%$ & $\mathbf{8 2 , 5 \%}$ \\
\hline Privada $(\Delta \%)$ & - & $7,6 \%$ & $4,7 \%$ & $3,5 \%$ & $3,9 \%$ & $3,3 \%$ & $2,9 \%$ & $13,6 \%$ & $\mathbf{5 , 6 \%}$ \\
\hline Totais & $\mathbf{5 . 4 7 8}$ & $\mathbf{5 . 9 6 9}$ & $\mathbf{6 . 2 2 4}$ & $\mathbf{6 . 4 1 3}$ & $\mathbf{6 . 6 1 8}$ & $\mathbf{6 . 8 2 8}$ & $\mathbf{7 . 0 0 5}$ & $\mathbf{7 . 8 1 0}$ & - \\
\hline$\triangle \%$ & - & $9,0 \%$ & $4,3 \%$ & $3,0 \%$ & $3,2 \%$ & $3,2 \%$ & $2,6 \%$ & $11,5 \%$ & $5,2 \%$ \\
\hline
\end{tabular}

(1) Médias aritméticas simples.

(2) (\%T) Indica o percentual relativo em relação ao total de Cursos ofertados no ano.

(3) $(\Delta \%)$ Indica a variação percentual ano a ano.

Fonte: Elaboração própria a partir dos dados das Sinopses Estatísticas da Educação Superior 2011-2018 - INEP/MEC.

A dinâmica de crescimento dos cursos e o predomínio das instituições privadas sobre as públicas podem ser visualizados por meio do Gráfico 1.

Gráfico 1 - Dinâmica dos cursos superiores de tecnologia ofertados e o predomínio das instituições privadas sobre as públicas - Brasil - 2011-2018

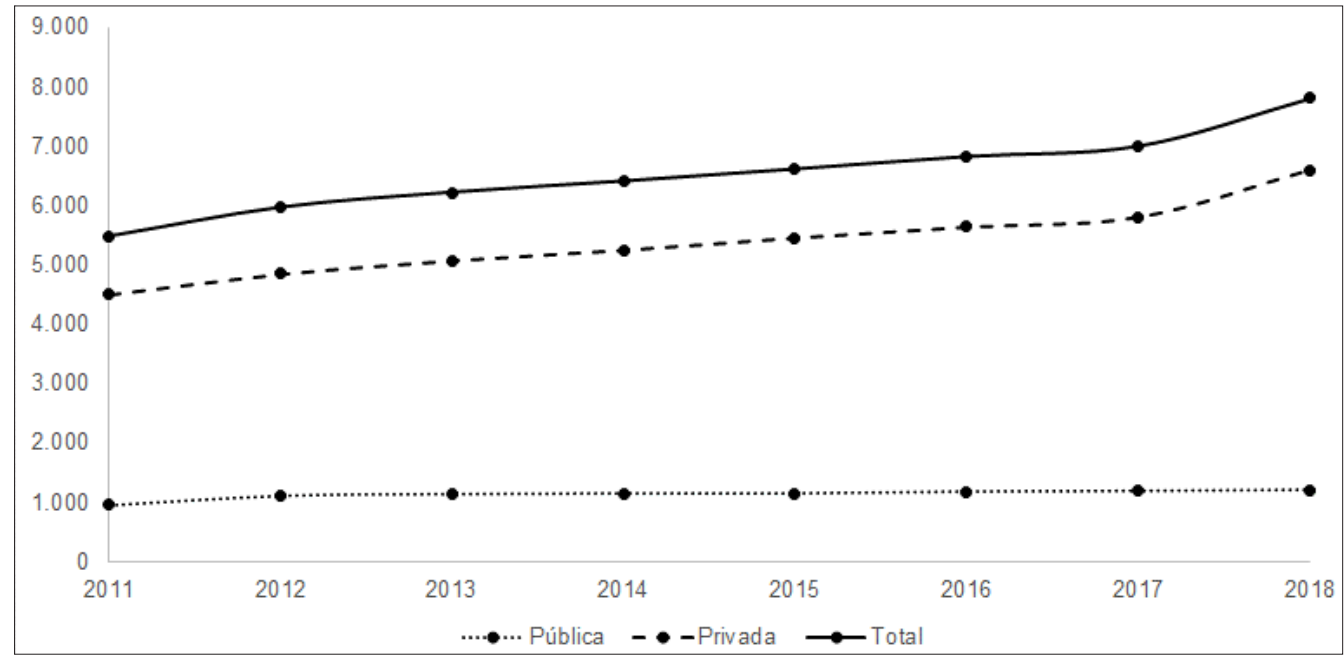

Fonte: Elaboração dos autores a partir dos dados das Sinopses Estatísticas da Educação Superior 2011-2018 - INEP/MEC. 
Tal predomínio do setor privado na EPT de nível superior fica ainda mais evidente ao se tomarem os dados de vagas ofertadas para o mesmo recorte temporal, os quais podem ser observados na Tabela 2. Em média, 96,1\% do total das vagas foram disponibilizadas por instituições privadas, contra apenas 3,9\% das vagas ofertadas por instituições públicas de ensino. Em 2011, foram abertas apenas 52.576 vagas de CST nas três esferas administrativas públicas (federal, estaduais e municipais) no país, contra mais de um milhão de vagas do setor privado. Em 2018, as instituições públicas somadas alcançaram um total de 75.244 vagas no país, com crescimento médio anual entre 2011 e 2018 de 5,7\% a.a. Já o setor privado chegou a 2018 com mais de três milhões de vagas e um crescimento médio anual de 17,2\% a.a. Neste último ano, 97,6\% do total de vagas ofertadas em CST foram disponibilizadas por instituições privadas no país.

A dinâmica de ofertas de vagas ao longo do período analisado não é uniforme. Como se pode verificar na Tabela 2, houve um expressivo aumento de vagas nas instituições públicas em 2012, na ordem de 25,7\% em relação ao ano anterior, com um decréscimo já no ano de 2013 (-3,4\%), voltando a aumentar as vagas em 2014 e 2015 e, novamente, diminuindo em 2016, para, então, um novo aumento em 2017, seguido de nova redução em 2018. Quanto à oferta do setor privado, essa se mostra um pouco mais uniforme, pois apresenta diminuição apenas no ano de 2015 (-9,5\%) em relação ao total de vagas de 2014. Foram observados pontos de significativos aumentos de vagas ao longo dos anos, atingindo o pico de 37,1\% em 2016, em relação ao ano imediatamente anterior. 


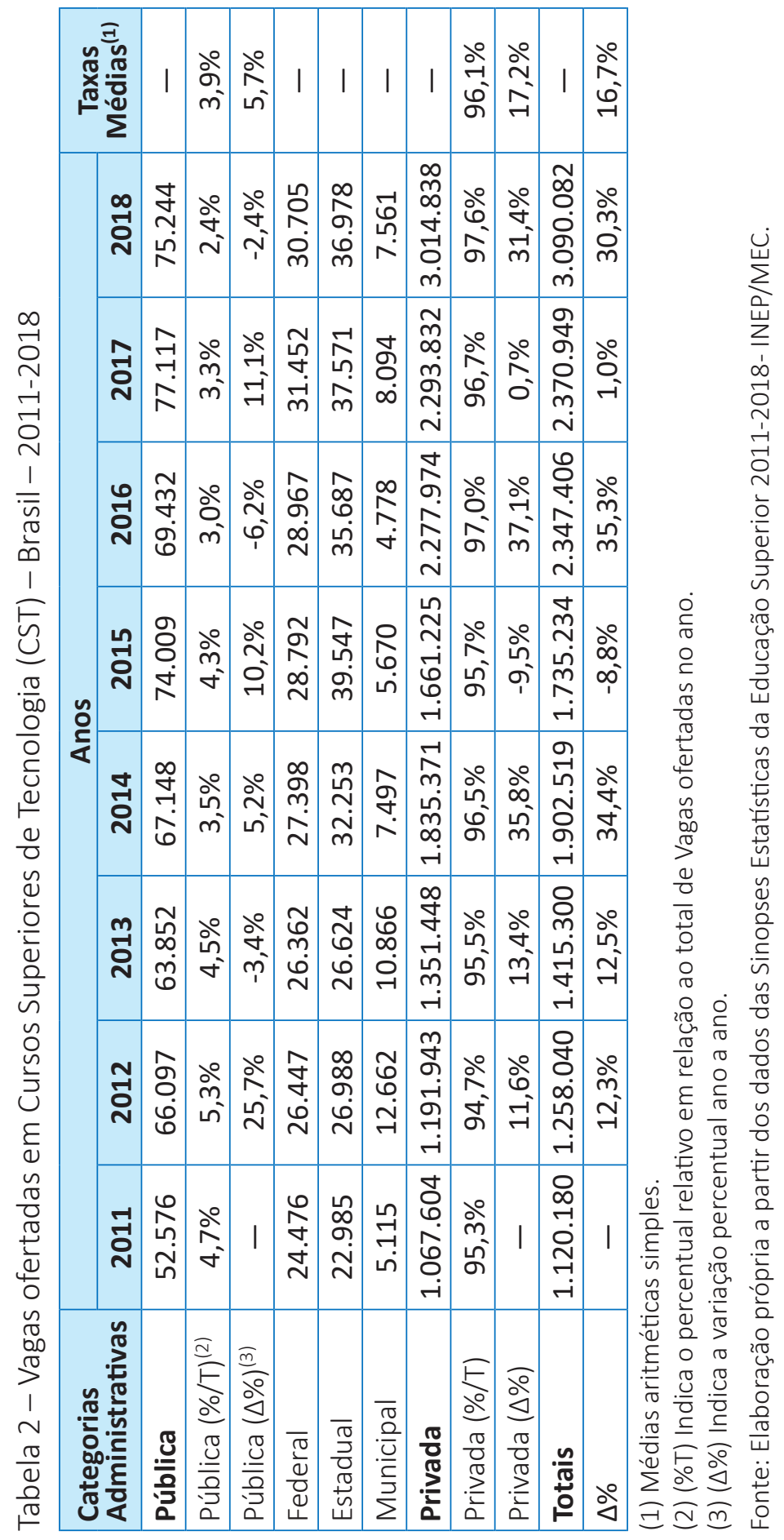


É possível afirmar, a partir dos dados analisados sobre vagas ofertadas, que o regime de expansão foi ditado pelas instituições do setor privado, o que fica evidente por meio da observação das taxas de variação percentual ( $\Delta \%)$ anuais. Dito de outra forma, é possível observar que, apesar da variação de sinais (acréscimo/ decréscimo de vagas) nas instituições públicas, o crescimento praticamente contínuo do setor privado promoveu o crescimento total de vagas ao longo do período, com um único decréscimo em 2015 (-8,8\%), em relação a 2014. Verificase, desse modo, um fenômeno de significativa expansão da oferta da Educação Profissional de nível superior, que vem sendo conduzida de modo hegemônico e sistemático pelo setor privado da educação. Este processo se consolida ao se observarem os números de matrículas efetivas realizadas para o mesmo recorte temporal. Essa dinâmica pode ser compreendida ao se observar o Gráfico 2.

Gráfico 2 - Vagas nos cursos superiores de tecnologia - Brasil - 2011-2018

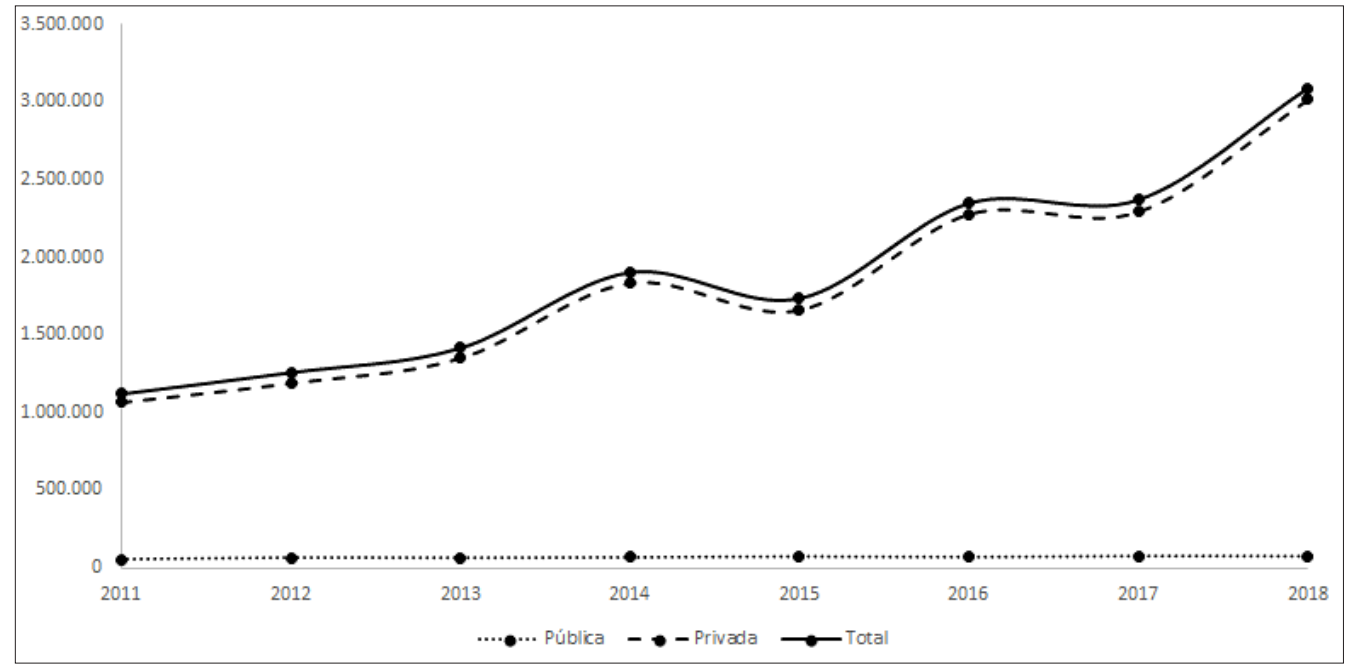

Fonte: Elaboração dos autores a partir dos dados das Sinopses Estatísticas da Educação Superior 2011-2018 - INEP/MEC.

Os dados de evolução das matrículas nos CST no Brasil estão disponibilizados na Tabela 3. Foi realizado um total de 870.534 matrículas nesses cursos em 2011 , sendo que $85,2 \%$ delas em instituições do setor privado, ou seja, 742.001 contra apenas 128.533 em instituições públicas, ou 14,8\%. As instituições da Rede Federal de EPT, entre as quais estão os Institutos Federais de Educação, 
Ciência e Tecnologia (IFECT), os Centros Federais de Educação Tecnológica (CEFET) e a Universidade Tecnológica Federal do Paraná (UTFPR), somaram 68.184 matrículas em 2011, o que representava aproximadamente 53\% do total de matrículas públicas, ficando os sistemas estaduais responsáveis por 56.121 matrículas, ou seja, aproximadamente $43,7 \%$, sendo a participação dos municípios praticamente irrisória, com 4.228 matrículas, o que representa praticamente 3,3\%. Essa configuração não se altera ao longo dos anos analisados, como se vê nas variações percentuais $(\Delta \%)$ anuais.

Tabela 3 - Matrículas em Cursos Superiores de Tecnologia (CST) ofertados Brasil - 2011-2018

\begin{tabular}{|c|c|c|c|c|c|c|c|c|c|}
\hline \multirow{2}{*}{$\begin{array}{c}\text { Categorias } \\
\text { Administrativas }\end{array}$} & \multicolumn{8}{|c|}{ Anos } & \multirow{2}{*}{$\begin{array}{c}\text { Taxas } \\
\text { Médias }^{(1}\end{array}$} \\
\hline & 2011 & 2012 & 2013 & 2014 & 2015 & 2016 & 2017 & 2018 & \\
\hline Pública & 128.533 & 140.935 & 143.169 & 142.289 & 149.209 & 157.000 & 163.664 & 168.526 & - \\
\hline Pública $(\% / T)^{(2)}$ & $14,8 \%$ & $14,9 \%$ & $14,4 \%$ & $13,8 \%$ & $14,8 \%$ & $16,6 \%$ & $16,4 \%$ & $15,3 \%$ & $15,1 \%$ \\
\hline Pública $(\Delta \%)^{(3)}$ & - & $9,6 \%$ & $1,6 \%$ & $-0,6 \%$ & $4,9 \%$ & $5,2 \%$ & $4,2 \%$ & $3,0 \%$ & $4,0 \%$ \\
\hline Federal & 68.184 & 64.424 & 61.975 & 63.118 & 68.862 & 73.951 & 76.502 & 77.308 & - \\
\hline Estadual & 56.121 & 62.318 & 67.323 & 73.397 & 76.699 & 79.726 & 84.558 & 88.750 & - \\
\hline Municipal & 4.228 & 14.193 & 13.871 & 5.774 & 3.648 & 3.323 & 2.604 & 2.468 & - \\
\hline Privada & 742.001 & 803.969 & 852.577 & 887.478 & 860.933 & 789.229 & 835.625 & 929.540 & - \\
\hline Privada $(\% / \mathrm{T})$ & $85,2 \%$ & $85,1 \%$ & $85,6 \%$ & $86,2 \%$ & $85,2 \%$ & $83,4 \%$ & $83,6 \%$ & $84,7 \%$ & $84,9 \%$ \\
\hline Privada $(\Delta \%)$ & - & $8,4 \%$ & $6,0 \%$ & $4,1 \%$ & $-3,0 \%$ & $-8,3 \%$ & $5,9 \%$ & $11,2 \%$ & $3,5 \%$ \\
\hline Totais & 870.534 & 944.904 & 995.746 & 1.029 .767 & 1.010 .142 & 946.229 & 999.289 & 1.098 .066 & - \\
\hline$\Delta \%$ & - & $8,5 \%$ & $5,4 \%$ & $3,4 \%$ & $-1,9 \%$ & $-6,3 \%$ & $5,6 \%$ & $9,9 \%$ & $3,5 \%$ \\
\hline
\end{tabular}

(1) Médias aritméticas simples.

(2) (\%T) Indica o percentual relativo em relação ao total de Matrículas do ano.

(3) $(\Delta \%)$ Indica a variação percentual ano a ano.

Fonte: Elaboração própria a partir dos dados das Sinopses Estatísticas da Educação Superior 2011-2018 - INEP/MEC.

Ao longo desses anos, as matrículas cresceram, em média, 3,5\% ao ano, sendo que as matrículas nas instituições públicas tiveram um crescimento relativo um pouco maior (4\% a.a.) quando comparadas àquelas das instituições privadas (3,5\% a.a.). No entanto é nítido o predomínio quantitativo de matrículas e, portanto, de alunos cursando o nível superior da Educação Profissional nas escolas privadas. Esta situação pode ser visualizada no Gráfico 3. 


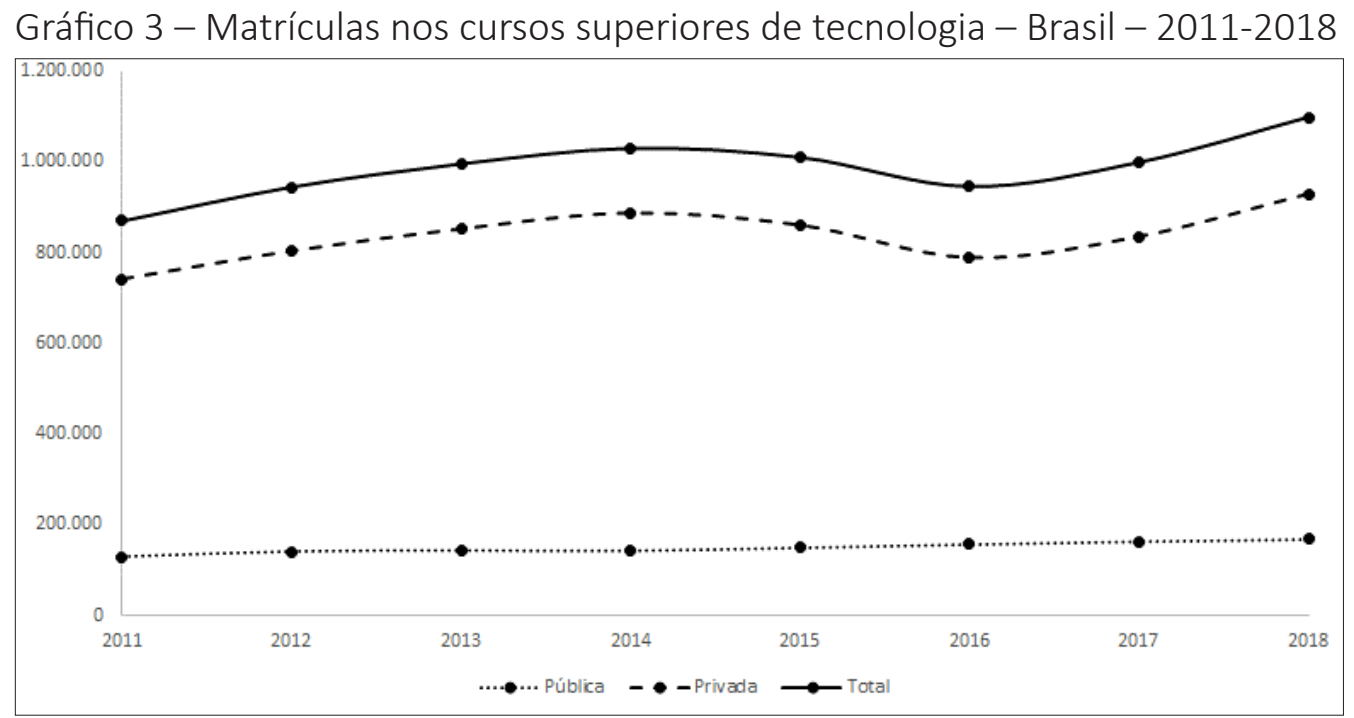

Fonte: Elaboração dos autores a partir dos dados das Sinopses Estatísticas da Educação Superior 2011-2018 - INEP/MEC.

Ao se tomarem os dados sobre matrículas nos CST no Estado de São Paulo, em particular, é possível verificar, por meio dos dados da Tabela 4, que houve um crescimento médio de 2,3\% ao ano no período de 2011 a 2018, portanto, inferior ao total do país. Observam-se dois anos de crescimento tenaz das matrículas, em que, em 2012, o crescimento foi de 8,5\% em relação ao ano anterior e, em 2013, foi de 5,0\% em relação a 2012. Houve dois anos consecutivos de decréscimos nas matrículas (2015 e 2016), seguidos de dois anos com crescimentos expressivos (4,2\% em 2017 e 9,4\% em 2018). Se eram pouco mais de 313 mil estudantes matriculados no primeiro ano da década (2011), esse número alcançou pouco mais de 362 mil estudantes em 2018. 


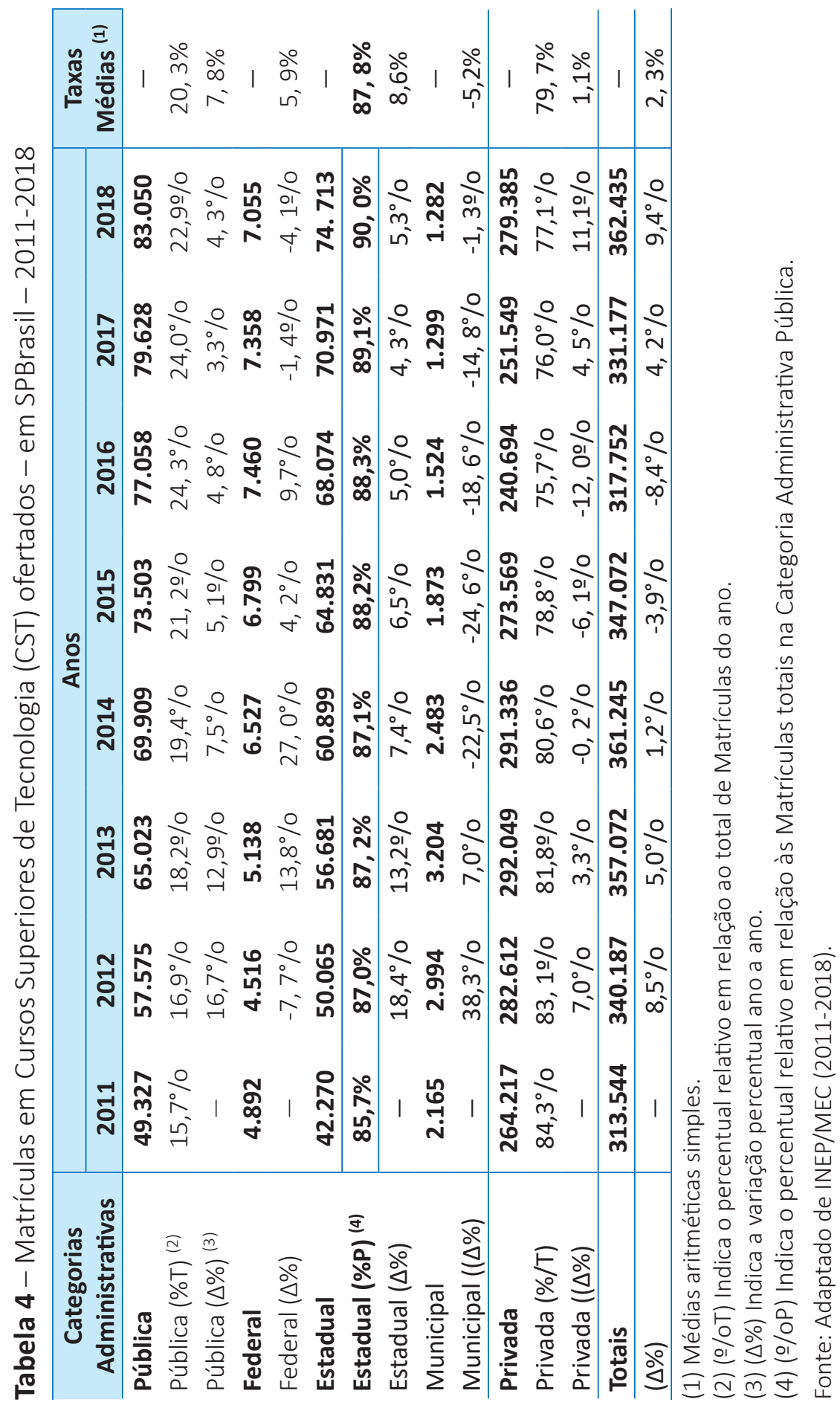


O predomínio da participação das instituições privadas nas matrículas também é verificável no estado de São Paulo, no qual a média ao longo dos anos foi de $79,7 \%$ contra apenas $20,3 \%$ das matrículas em instituições públicas dos três níveis administrativos. No entanto a expansão das matrículas, em termos relativos, foi superior nas instituições públicas (média de 7,8\% a.a. no período 2011-2018) em relação às instituições privadas (média de 1,1\% a.a.), como se observa nos dados da Tabela 4.

Entre as instituições públicas ofertantes de cursos superiores de tecnologia, o predomínio do Ceeteps é evidente, desde 2011. No ano de 2018, as 74.713 matrículas nessa instituição representavam 90\% do total de matrículas nas instituições públicas, enquanto as instituições da Rede Federal de EPT foram responsáveis por 7.055 matrículas, o que representa aproximadamente 8,5\% do total de 83.050 matrículas. O predomínio da rede estadual na educação tecnológica de nível superior também se evidencia pela taxa média de crescimento das matrículas, a qual foi de 8,6\% a.a. no período de 2011 a 2018, enquanto na Rede Federal de EPT esse crescimento médio foi de 5,9\% a.a. Adicionalmente, pode-se verificar que as 74.713 matrículas efetuadas no Centro Paula Souza em 2018 representam aproximadamente $44,3 \%$ de todas as 168.526 matrículas em cursos superiores de tecnologia de todo o país.

\section{OS CURSOS SUPERIORES DE TECNOLOGIA E A INTERNACIONALIZAÇÃO DA EDUCAÇÃO: POR UMA INSERÇÃO NA POLÍTICA NACIONAL DE CIÊNCIA, TECNOLOGIA E INOVAÇÃO}

O Catálogo Nacional de Cursos Superiores de Tecnologia (CNCST) está em sua terceira edição, publicada no ano de 2016. Esta edição mais recente foi construída coletivamente a partir da participação de professores, especialistas e pesquisadores, entidades representativas das instituições de educação superior e entidades de representação profissional. Também por intermédio de consulta pública foram recebidas e incorporadas ao documento sugestões para sua elaboração final.

Sendo um momento de síntese, o Catálogo demonstra o esforço de instituições de ensino, policy makers, setor produtivo, estudantes e profissionais no sentido de ampliar e garantir a ampliação da oferta de CST não simplesmente em termos quantitativos, mas também colocando em pauta uma perspectiva 
ampliada de formação profissional e tecnológica. Nos termos expressos no Catálogo, é importante

[...] qualificar a oferta dos CST e formar profissionais cada vez mais aptos a desenvolver, de forma plena e inovadora, as atividades próprias de cada curso tecnológico, com capacidade para utilizar, desenvolver ou adaptar tecnologias com a compreensão crítica das implicações daí decorrentes e das suas relações com o processo produtivo, o ser humano, o ambiente e a sociedade. (BRASIL, 2016, p. 8).

A internacionalização na formação dos tecnólogos aparece, nos catálogos, de maneira pontual associada a eixos tecnológicos específicos, como são os casos dos eixos Turismo, Hospitalidade e Lazer, Informação e Comunicação, Gestão e Negócios, e o eixo Militar.

É possível vislumbrar a relevância que foi dada a esse tipo de formação na primeira década dos anos 2000, quando se analisa a proposta do Programa Ciência sem Fronteiras, no qual se destacava a relevância dos institutos de formação profissional e tecnológica no desenvolvimento de ações de mobilidade internacional de discentes, levando em conta as particularidades da EPT, em especial dos cursos superiores de tecnologia. Essa foi uma perspectiva ampliada não só de EPT, mas das potencialidades da internacionalização de suas instituições.

O programa Ciência sem Fronteiras, instituído pelo Decreto n. 7.642, de 13 de dezembro de 2011 (BRASIL, 2011), propunha a mobilidade acadêmica internacional em um contexto de desenvolvimento da política de ciência, tecnologia e inovação (CT\&I), na medida em que seu objetivo era:

[...] a formação de recursos humanos altamente qualificados nas melhores universidades e instituições de pesquisa estrangeiras, com vistas a promover a internacionalização da ciência e tecnologia nacional, estimular pesquisas que gerem inovação e, consequentemente, aumentar a competitividade das empresas brasileiras. (COORDENAÇÃO DE APERFEIÇOAMENTO DE PESSOAL DE NÍVEL SUPERIOR [CAPES], 2011, p. 1).

O programa apresentava, no contexto da época de sua propositura e implementação, potencial de articular ações de Educação e CT\&I na conjuntura internacional da aceleração dos processos de globalização de mercados e financeirização da economia, com acirrada competitividade empresarial pautada por inovações oriundas de progressos técnico-científicos. Essa articulação aparece no texto do próprio Decreto n. 7.642, ao deixar claro que as ações do programa 
complementam as atividades de cooperação internacional conduzidas pela CAPES, do MEC e do Conselho Nacional de Desenvolvimento Científico e Tecnológico (CNPq), do então Ministério da Ciência, Tecnologia e Inovação (MCTI).

A EPT estava contemplada desde o nível técnico no programa. A significativa relação estratégica entre educação, trabalho e CT\&l na busca pela inserção internacional das instituições de pesquisa e da própria educação orientada à alfabetização científica fica clara nesse documento legal, ao se verificar que, no art. 4으, estavam previstos no Comitê de Acompanhamento e Assessoramento do referido programa, entre outros atores institucionais, um representante do MEC, um do MCTI, um do Ministério das Relações Exteriores e um do Ministério do Desenvolvimento, Indústria e Comércio Exterior. Outra marca relevante da articulação entre Educação e CT\&I que se pode extrair do documento é o fato de que a presidência do mencionado Comitê de Acompanhamento e Assessoramento seria alternada, a cada intervalo de doze meses, entre os representantes do MEC e do MCTI. Já quanto ao comitê executivo do programa, além dos representantes desses ministérios citados, estavam incluídos os presidentes do CNPq e da CAPES. A mesma alternância da coordenação do comitê de acompanhamento e assessoramento se verificava para o comitê executivo, tendo, dessa forma, protagonismo os respectivos ministros da Educação e da CT\&I (BRASIL, 2011).

Embora a articulação entre a internacionalização da educação, em especial da EPT, no formato de mobilidade com a política de ciência, tecnologia e inovação, tenha avançado com o Programa Ciências sem Fronteiras, há de se considerar a descontinuidade dessa política e mesmo desse programa em especial. Somada a essa descontinuidade a partir de 2016, é possível observar que os intercambistas que usufruíram do Programa comumente retornaram ao país e não encontraram espaço institucional para divulgar e potencializar suas experiências (PINTO; LARRECHEA, 2018).

Experiências de internacionalização da EPT têm demonstrado que é preciso vencer barreiras socioculturais que relegam esse tipo de formação a um patamar de formação de segunda classe diante do bacharelado. Os debates, avanços e recuos quanto aos mestrados e doutorados profissionais são representativos desse desafio.

As características da formação superior do tipo tecnológica não estão distantes das tendências internacionais quanto a uma formação de caráter mais 
prático, profissionalizante e de menor tempo. Configura-se na Europa, a partir do Processo de Bolonha, o que Azevedo (2006) designa como políticas educacionais de caráter transnacional, com particular destaque, atualmente, para a educação superior concebida como um sistema internacional, visando à potencialização da internacionalização.

Em Portugal, por exemplo, cursos similares aos nossos cursos superiores de tecnologia são os cursos técnicos superiores profissionais, que se enquadram em um processo de massificação do ensino no país, cuja oferta educativa teve de se ampliar substancialmente, inclusive por questões demográficas e por acordos políticos provenientes de sua participação na comunidade europeia, de modo que os diferentes ciclos precisaram se flexibilizar e permitir um acesso maior. Experiências nessa direção já se percebiam nos anos 1970 com a oferta dos cursos superiores politécnicos (CENTRO EUROPEU PARA O DESENVOLVIMENTO DA FORMAÇÃO PROFISSIONAL [CEDEFOP], 1999), mas o fator que vai intensificar esse modelo será efetivamente o Processo de Bolonha.

É importante que se considere que a internacionalização da EPT é parte da agenda mundial e da agenda brasileira. A formação dessa agenda tem uma forte influência da geopolítica e das relações econômicas que estão intrinsicamente vinculadas ao processo educacional de formação de trabalhadores em contextos cada vez mais globalizados, sem desconsiderar a complexidade dos interesses e das estratégias dos blocos regionais.

\section{CONSIDERAÇÕES FINAIS}

Os cursos superiores de tecnologia no Brasil são comumente confundidos com os cursos técnicos de nível médio, e isso se deve não somente à desinformação, mas também à maneira como, no país, entende-se a formação técnica, considerada de importância social menor, tendo comprometimentos na inserção laboral do egresso. Cinquenta anos de cursos superiores de tecnologia não foram suficientes para que se tenha uma percepção ampla e irrestrita de que essa é uma oferta educativa de nível superior com um enfoque profissionalizante. O caráter profissionalizante e aligeirado dos cursos superiores de tecnologia fizeram com que ainda se tenha uma ideia de que esses cursos não seriam cursos superiores plenos. Mas esse mesmo caráter profissionalizante e aligeirado tem justificado a expansão da rede privada de ensino superior na oferta de 
bacharelados compactos, seja no formato presencial, seja no semipresencial ou a distância.

Por serem oferecidos inicialmente por instituições não universitárias, ainda se entende que esses cursos devam ser mais limitados do ponto de vista científico e tecnológico, o que não era exatamente a concepção de instituições como o Ceeteps, que foi concebido como um centro tecnológico. Ao se opor a formação propedêutica de caráter geral e científico à formação profissional, corre-se o risco de reforçar a ideia, bastante generalizada, de que à universidade e ao ensino superior de maneira geral caberia apenas o papel de certificação e titulação, e não necessariamente de formação profissional e tecnológica. Essa tarefa estaria restrita a uma espécie de educação corporativa oferecida como treinamento nas grandes corporações, empresas de pequeno e médio porte e instituições públicas não educacionais (ALMEIDA FILHO, 2007). Essa concepção historicamente construída que colocou o tecnólogo como um profissional em contraponto ao bacharel precisa ser problematizada, na medida em que todos os níveis de educação estão subsumidos à lógica da profissionalização e à teoria do capital humano, havendo o desafio de se questionar cotidianamente quais sãos os objetivos da formação científica e tecnológica.

Cursos superiores profissionalizantes e cursos técnicos superiores são terminologias que se mostram muito estranhas no contexto brasileiro, por haver uma concepção de que a formação em nível superior é distante ou deveria ser distante, ou ainda que está perigosamente se aproximando da formação de caráter estritamente profissionalizante. O fato é que a formação profissional e tecnológica de nível superior não precisa ser mais estritamente profissionalizante e nem a formação universitária tem se mantido tão distante das exigências do mundo do trabalho, crescentemente internacionalizado.

Neste artigo, podemos apresentar a trajetória dos cursos superiores de tecnologia associada, principalmente, a uma instituição de ensino superior pública não universitária, o Ceeteps, ao qual estão vinculadas as Faculdades de Tecnologia (Fatec). Desde o fim dos anos 1960, surgiram várias outras instituições públicas e privadas de educação superior que não são universidades e que oferecem cursos superiores de tecnologia nas mais variadas áreas do conhecimento e nas diversas atividades econômicas, colocando novos desafios para esse tipo de formação, que se vê enredada na formação imediata para o mercado de trabalho 
e se distanciando do que poderia ser sua especificidade, ou seja, a densidade tecnológica. Uma educação tecnológica efetiva, ao se considerar a centralidade da tecnologia na EPT, é uma tarefa ainda a se realizar, mas isso implica em pensar em outros modelos de desenvolvimento.

A multiplicação de instituições privadas de ensino superior e a expansão das redes estaduais de EPT no formato não universitário trouxeram formatos institucionais bem distantes daquela ideia inicial de centros tecnológicos, como foi, por exemplo, a aposta no Ceeteps.

$\mathrm{Na}$ época do seu surgimento, os cursos superiores de tecnologia estavam alinhados ao nacional-desenvolvimentismo profundamente marcado pela influência norte-americana. Esse cenário fez surgir uma instituição como o Ceeteps, que era pensada pelos seus primeiros atores como um grande centro tecnológico. Acontecendo a expansão da EPT, a formação dos tecnólogos teve novos contornos ao ser ampliada às mais variadas áreas do conhecimento e setores da atividade produtiva, fazendo-se necessário repensar a natureza e o sentido dessa formação já distanciada de uma formação tecnicista, mas longe de ser tecnológica, no sentido que damos a esse termo ao longo do nosso estudo. Percebe-se que há um problema de fundo a ser investigado, que é a polissemia das palavras tecnologia e tecnológico quando aplicadas à formação profissional. O que significava formar efetivamente um grande centro tecnológico formador de tecnólogos no fim dos anos 1960? Que sentido foi dado a isso ao longo da implementação e consolidação dos cursos superiores de tecnologia? Certamente a resposta a essas questões estão muito distantes do que se pode propor, como o protagonismo do Brasil em cenários regionais e internacionais do ponto de vista tecnocientífico.

Com o fenômeno da globalização e a expansão da oferta educativa pública de EPT em nível estadual e municipal nos anos 2000, vislumbrou-se, para os cursos de tecnologia e as instituições que oferecem esses cursos, um lugar estratégico diante da internacionalização da ciência e da tecnologia nacional. A tentativa era de garantir o estímulo às pesquisas geradoras de inovação e o compromisso com a formação de novos quadros de trabalhadores em geral e pesquisadores que, internacionalizados, poderiam contribuir com a inserção regional e mundial do país. Com as reformulações educacionais e institucionais em curso em parte marcadas pela Reforma do Ensino Médio de 2017 e o corte 
de gastos para as universidades, vê-se uma tendência considerável em continuar a internacionalização da educação em um sentido que pouco resulta para além das experiências multiculturais dos sujeitos.

O espírito da profissionalização atravessa toda a trajetória escolar, em que inovação e empreendedorismo se tornam valores educacionais já nos primeiros anos da escola, inclusive sofrendo influências de organismos internacionais. Mas esse espírito da profissionalização, que não mais nos permite separar de forma simplista uma formação propedêutica de uma formação profissional, também não nos impede de reconhecer a especificidade dos sistemas ou arranjos educacionais voltados para a educação profissional e tecnológica, que, passados os anos de expansão, veem-se em novos enfrentamentos diante da internacionalização da educação e, ao mesmo tempo, perante a precarização do trabalho e da própria concepção de formação técnica e tecnológica, restrita à simples qualificação profissional, dissociada do processo de escolarização. Ao mesmo tempo que verificamos a existência há 50 anos dos cursos superiores de tecnologia e o surgimento e ampliação da pós-graduação na modalidade profissional, pode-se perceber as políticas educacionais em curso sendo voltadas para a qualificação, visando à inserção imediata do egresso no mercado de trabalho, a despeito do seu nível de escolaridade.

\section{REFERÊNCIAS}

ALMEIDA FILHO, Naomar. Universidade nova: textos críticos e esperançosos. Brasília: UnB; Salvador: EDUFBA, 2007.

AZEVEDO, Mário Luiz N. A integração dos sistemas de educação superior na Europa: de Roma a Bolonha ou da integração econômica à integração acadêmica. In: SILVA JR., João dos Reis; OLIVEIRA, João Ferreira de; MANCEBO, Deise (Org.). Reforma universitária: dimensões e perspectivas. Campinas, SP: Alínea, 2006. p. 171-86.

BATISTA, Sueli Soares dos S. Educação profissional e tecnológica: politecnia e emancipação. In: ALMEIDA, Ivanete B.; BATISTA, Sueli Soares dos S. (Org.). Educação tecnológica: reflexões, teorias e práticas. São Paulo: Paco Editorial, 2012. p. 27-38.

BRANDÃO, Marisa. Cursos superiores de tecnologia: democratização do acesso ao ensino superior? Revista Trabalho Necessário, ano 5, n. 5, 2007. Disponível em: https://periodicos. uff.br/trabalhonecessario/article/view/4607. Acesso em: 5 ago. 2020. 
Cursos superiores de tecnologia no contexto da internacionalização e da expansão da educação profissional e tecnológica no Estado de São Paulo

BRASIL. Ministério da Educação. Catálogo Nacional de Cursos Superiores de Tecnologia (CNCST). 2016. Disponível em: http://portal.mec.gov.br/index.php?option=com docman\&view=download\&alias=44501-cncst-2016-3edc-pdf\&category_slug=junho2016-pdf\&Itemid=30192. Acesso em: 22 out. 2017.

BRASIL. Presidência da República. Casa Civil. Decreto n. 7.642, de 13 de dezembro de 2011. Institui o Programa Ciência sem Fronteiras. Diário Oficial da União, Brasília, 14 dez. 2011. Disponível em: http://www.planalto.gov.br/ccivil_03/_ato2011-2014/2011/ decreto/d7642.htm. Acesso em: 22 out. 2019.

COORDENAÇÃO DE APERFEIÇOAMENTO DE PESSOAL DE NÍVEL SUPERIOR (CAPES). Ciência sem fronteiras: um programa especial de mobilidade internacional em Ciência, Tecnologia e Inovação. 2011. Disponível em: http://www.capes.gov.br/images/stories/download/ Ciencia-sem-Fronteiras_DocumentoCompleto_julho2011.pdf. Acesso em: 2 out. 2019

CARVALHO, Alan Henrique Pardo. A formação tecnológica e os cursos sequenciais: uma visão do corpo docente de um curso sequencial da área de tecnologia da informação. 2005. Dissertação (Mestrado em Tecnologia) - Centro Estadual de Educação Tecnológica Paula Souza (Ceeteps), São Paulo, 2005.

CASTRO, Claudio de Moura. Os community colleges: uma solução viável para o Brasil? Brasília: Instituto Nacional de Estudos e Pesquisas Educacionais, 2000. (Série Documental. Textos para discussão).

CENTRO EUROPEU PARA O DESENVOLVIMENTO DA FORMAÇÃO PROFISSIONAL (CEDEFOP). 1999. O Sistema de Formação Profissional em Portugal. Disponível em: https://www. cedefop.europa.eu/files/7009_pt.pdf. Acesso em: 30 set. 2019

CONSELHO FEDERAL DE ENGENHARIA, ARQUITETURA E AGRONOMIA. (CONFEA). Resolução $n$. 313, de 26 de setembro de 1986. Dispõe sobre o exercício profissional dos Tecnólogos das áreas submetidas à regulamentação e fiscalização instituídas pela Lei n. 5.194, de 24 dez. 1966, e dá outras providências. Disponível em: http://normativos. confea.org.br/ementas/visualiza.asp?idEmenta=361\&idTipoEmenta=5\&Numero=. Acesso em: 12 dez. 2019.

FIALA, Diane Andreia de Souza. A política de expansão da educação profissional e tecnológica de graduação pública no estado de São Paulo (2000-2007). 2016. Dissertação (Mestrado em Educação)- Universidade Estadual de Campinas, Campinas, SP, 2016.

GONÇALVES, Rafael. Educação tecnológica e empregabilidade: acompanhamento de egressos da Fatec-SP. 2007. Dissertação (Mestrado em Tecnologia) - Centro Estadual de Educação Tecnológica Paula Souza (Ceeteps), São Paulo, 2007. 
INSTITUTO NACIONAL DE ESTUDOS E PESQUISAS EDUCACIONAIS ANÍSIO TEIXEIRA. Sinopses Estatísticas da Educação Superior 2011-2018. Brasília: Inep, 2011-2018. Disponíveis em: http://inep.gov.br/censo-da-educacao-superior. Acesso em: 2 out. 2019.

MACHADO, Lucília Regina de Souza. O profissional tecnólogo e sua formação. In: BUENO, Maria Sylvia Simões; ALVES, Giovanni (Org.). Trabalho, educação e formação profissional: perspectivas do capitalismo global. Campinas, SP: Autores Associados, 2008.

MARTINS, Carlos Benedito. A reforma universitária de 1968 e a abertura para o ensino superior privado no Brasil. Educação \& Sociedade, Campinas, SP, v. 30, n. 106, p. 15-35, jan./abr. 2009.

MOTOYAMA, Shozo (Org.). Educação técnica e tecnológica em questão: 25 anos do Ceeteps - uma história vivida. São Paulo: Editora da Unesp: CEETEPS, 1995.

OLIVEIRA, Regina Rita de Cássia. Cursos "superiores" de curta duração - esta não é uma conversa nova. Revista Educação Tecnológica, Belo Horizonte, v. 8, n. 2, p. 18-25, jul./ dez. 2003.

OLIVEIRA, Ramon. Jovens, ensino médio e educação profissional. São Paulo: Papirus, 2012.

PINTO, Marialva Moog; LARRECHEA, Enrique Martínez Larrechea. Internacionalização da educação superior: uma análise das tendências de mobilidade dos estudantes entre países do norte e do sul global. Revista Avaliação (Campinas), Sorocaba, SP, v. 23, n. 3, p. 718-35, set./dez. 2018.

SANTOS, Lincoln de Araújo. A alternativa para o progresso: o nacionalismodesenvolvimentista, seus intelectuais e o planejamento educacional dos anos 1960 no Brasil. Revista Brasileira de História da Educação, Maringá, PR, v. 19, e057, 2019.

TEIXEIRA, Anísio. Educação no Brasil. São Paulo: Nacional, 1969.

\section{Sobre os autores:}

Sueli Soares dos Santos Batista: Pós-doutorado realizado no Dep. de História e Filosofia da Educação da Faculdade de Educação da Unicamp. Doutorado e mestrado em Psicologia da Aprendizagem e do Desenvolvimento Humano pela Universidade de São Paulo (USP). Graduação em História pela USP, e em Filosofia pela Unicamp. Professora e pesquisadora do Mestrado Profissional do Centro Estadual de Educação Tecnológica Paula Souza (CEETEPS). Coordenadora do 
Núcleo de Estudos de Tecnologia e Sociedade (NETS-Fatec Jundiaí) e do Grupo de Fundamentos da Educação Profissional e Tecnológica vinculado à pós-graduação. E-mail: suelissbatista@uol.com.br, Orcid: http://orcid.org/0000-0001-8126-9615

Emerson Freire: Pós-Doutorado realizado no Departamento de Sociologia da Unicamp. Doutor em Sociologia pela Universidade Estadual de Campinas, e em Filosofia, pela Université de Paris 1 - Panthéon Sorbonne - França. Mestrado em Política Científica e Tecnológica pela Universidade Estadual de Campina. Professor e pesquisador no Mestrado em Educação Profissional do Centro Estadual de Educação Tecnológica Paula Souza (CEETEPS) e na Fatec Jundiaí, onde coordena o Núcleo de Estudos de Tecnologia e Sociedade (NETS). E-mail: freire.emerson@uol.com.br, Orcid: http://orcid.org/0000-0001-5449-2002

Darlan Marcelo Delgado: Pós-doutorado em Educação, realizado no Departamento de Educação (DEd) da Universidade Federal de São Carlos (UFSCar). Doutor em Educação Escolar. Mestre em Educação pela Universidade Estadual Paulista (UNESP). Bacharel em Ciências Econômicas pela Universidade de São Paulo (USP), e licenciado em Matemática pelo Centro Universitário Claretiano de Batatais. Professor de Nível Superior III, em Regime de Dedicação Exclusiva no Centro Estadual de Educação Tecnológica Paula Souza (CEETEPS), trabalhando na Unidade de Pós-Graduação, Extensão e Pesquisa - Mestrado Profissional em Gestão e Desenvolvimento da Educação Profissional, e na Faculdade de Tecnologia de Mococa, SP (FATEC Mococa). E-mail: profdarlandelgado@gmail.com, Orcid: http://orcid.org/0000-0003-3177-2364

Recebido em 10 de outubro de 2019.

Aprovado em 15 de maio de 2020. 
